\title{
Hypocapnia Induced by Involuntary Hyperventilation during Mental Arithmetic Reduces Cerebral Blood Flow Velocity
}

\author{
Róbert Debreczeni, ${ }^{1}$ Ilona Amrein, ${ }^{1}$ Anita Kamondi ${ }^{1}$ and Imre Szirmai ${ }^{1}$ \\ ${ }^{1}$ Department of Neurology, Faculty of Medicine, Semmelweis University, Budapest, Hungary
}

Functional neuroimaging studies have shown that cognitive processes increase regional cerebral blood flow in relation with enhanced neuronal activity. However, cognition induces elevation of blood pressure, heart rate and respiratory rate, each of which also affects cerebral circulation. For proper interpretation of functional neuroimaging data, it is necessary to dissociate the effects of systemic and local metabolic reactions on regional cerebral circulation. To elucidate this interaction, we examined the changes in cerebral blood flow velocity, which were caused by voluntary hyperventilation-induced hypocapnia without cognitive effort and hypocapnia evolving during mental arithmetic task. The cerebral blood flow velocity was recorded in the middle cerebral arteries, using transcranial Doppler sonography. Respiratory rate, end-tidal partial pressure of $\mathrm{CO}_{2}$, heart rate and arterial blood pressure were simultaneously monitored. Data were statistically evaluated. Hypocapnia induced by voluntary hyperventilation without cognition decreased the cerebral blood flow velocity. During mental arithmetic, the cerebral blood flow velocity first increased, but the hypocapnia, which was induced by involuntary hyperventilation related to cognitive effort, reduced it. This implies temporary vasoconstriction of cerebral microvessels, and the increase in cerebral vascular resistance index supports this finding. These results suggest that hypocapnia, which develops during cognition, may decrease blood flow velocity in the middle cerebral arteries, which interferes with the neuronal activitydriven regulation of cerebral circulation. In conclusion, when interpreting the results of functional neuroimaging studies on cognitive mechanisms, the tight coupling of the effects of mental processes and autonomic/metabolic reactions should be considered. —— Transcranial Doppler sonography; mental arithmetic; hypocapnia; heart rate; blood pressure.

Tohoku J. Exp. Med., 2009, 217 (2), 147-154. (C) 2009 Tohoku University Medical Press

Cognitive efforts induce lateralized hemodynamic changes in the cerebral hemispheres, which can be demonstrated by blood flow velocity (BFV) measurements using transcranial Doppler sonography (TCD) (Droste et al. 1989; Hartje et al. 1994; Schmidt et al. 1999; Deppe et al. 2004). The validity of Doppler data has been proven by functional magnetic resonance imaging (fMRI) studies (Schmidt et al. 1999; Weiss et al. 2003). Beside localized increase of cerebral blood flow, cognitive effort also induces considerable autonomic changes, including the elevation of arterial blood pressure (ABP), heart rate (HR) and respiratory rate (Rr) (Oldfield 1971; Moody et al. 2005; Yoshino and Matsouka 2005). These systemic factors also influence cerebral circulation, and their effects should always be considered when interpreting both functional TCD and functional MRI results (Stroobant and Vingerhoets 2000). However, due to technical difficulties, the parallel measurement of cerebral blood flow and cardiac- as well as respiratory autonomic parameters has been performed only in few cases (Wang et al. 2005). In our previous study (Szirmai et al. 2005), in which we described the correlation between blood flow velocity and central frequency of EEG, we found that dur- ing cognitive tests, after a transitory increase, blood flow velocity returned almost to the initial level, despite increasing blood pressure and heart rate. These observations suggested analogy with the physiological effect of hyperventilation induced vasoconstriction (Malatino et al. 1992), because temporary decrease of flow velocity could not be explained by the metabolic- and/or neurogenic theory of cerebral blood flow regulation. We presumed that the unexpected decrease of blood flow velocity was due to hypocapnia evoked by hyperventilation, and that this systemic effect interfered with the local cerebral circulatory changes induced by cognitive processes. Similar results were found by fMRI investigations performed during controlled hyperventilation (Posse et al. 1997).

In the present study, we investigated the interactions between cognition-induced changes in cerebral circulation and changes in autonomic functions by simultaneously recording blood flow velocity in the middle cerebral arteries (MCA) and cardiac as well as respiratory parameters during mental arithmetic task.

Received November 10, 2008; revision accepted for publication January 19, 2009.

Correspondence: Anita Kamondi MD., Ph.D., Department of Neurology, Semmelweis University, 1083 Budapest, Balassa u. 6. Hungary.

e-mail: kamondianita@gmail.com 


\section{Materials And Methods}

Subjects

Sixteen healthy right-handed volunteers were investigated (6 male, mean age: $35.8 \pm 12.1$ years). Handedness was determined by the Edinburgh Handedness Inventory (Oldfield 1971). Subjects were informed about the research procedure before giving written consent. The experiment was approved by the Ethical Committee of the Semmelweis University.

The investigation was carried out in a quiet room, subjects were in supine position with closed eyes and were instructed not to speak and avoid soliloquizing. All signals and instructions were presented through loudspeaker. The entire session lasted for 1.5 hours.

\section{Recordings and data processing}

Blood flow velocity $(\mathrm{BFV} ; \mathrm{cm} / \mathrm{s})$ was recorded using transcranial Doppler sonography (2-MHz pulsed-wave DWL Multidop-T, Sipplingen, Germany). Transducers were adjusted bilaterally using a metallic holder to obtain maximal signal intensity of both middle cerebral arteries at the depth of 45-55 mm. The software of the TCD equipment generated envelope curves derived from maximum frequency peaks of BFV after fast-Fourier transformation. The sampling rate was $57 \mathrm{~Hz}$. ASCII files provided by the Multidop-T software were stored on hard disk for off-line analysis. Artefacts were rejected by linear interpolation after visual screening.

The left-right difference of BFV at a given time was calculated by subtracting the corresponding right relative values from the left relative ones (for calculation of relative values see Statistics). Positive number represented higher relative blood flow velocity in the left MCA.

Arterial blood pressure (ABP; $\mathrm{mmHg}$ ) was recorded beat-tobeat over the left radial artery using a non-invasive radial tonometry method (Colin-508T, Colin Corporation, Komaki City, Japan) (Nelesen and Dimsdale 2002). Calibration to $\mathrm{mmHg}$ before and after the cognitive test was performed by the same equipment's sphygmomanometer.

Running averages of BFV and ABP were calculated using $5 \mathrm{~s}$ analysis intervals with $0.5 \mathrm{~s}$ stepping (Fig. 1B). To compute mean $\mathrm{BFV}$ and beat-to-beat $\mathrm{ABP}$ we used equations 1 and 2:

Eq. $1: \mathrm{BFV}=(\mathrm{Vsys}+2 \mathrm{Vdia}) / 3$; and

Eq. $2: \mathrm{ABP}=($ ABPsys $+2 \mathrm{ABPdia}) / 3$,

where Vsys is the maximal systolic, Vdia is the end diastolic ve-

\section{A}

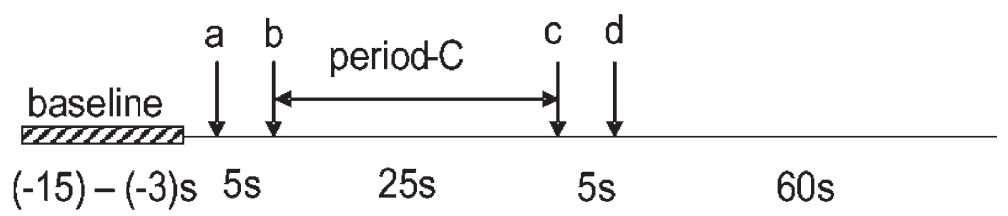

$\mathrm{B}$

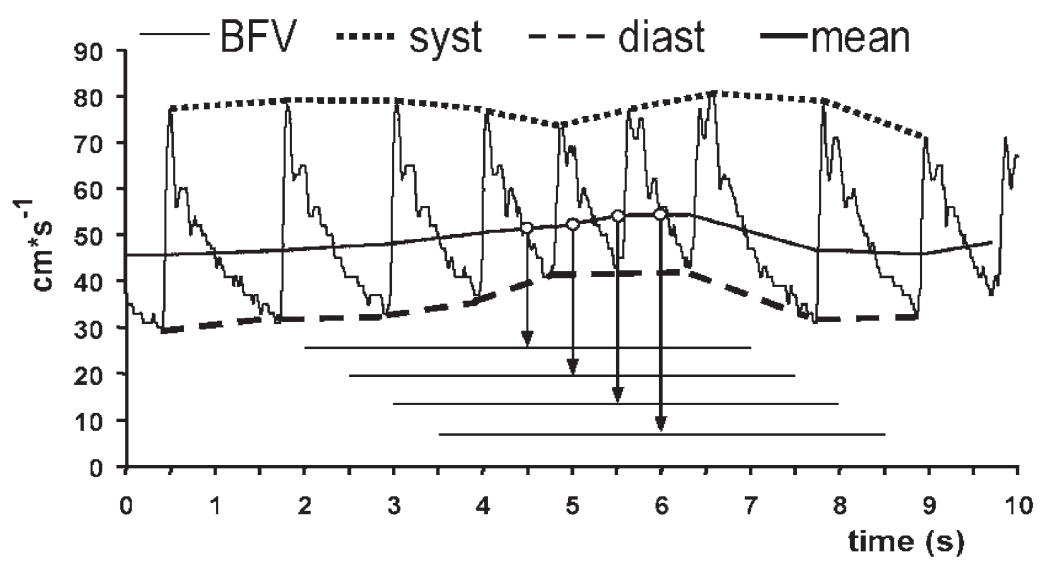

Fig. 1. Mental arithmetic paradigm.

A. Flow chart of the mental arithmetic paradigm. Signal-a: presentation of the task; signal-b: start of calculation; signal-c: end of calculation; signal-d: declaring the result of calculation; period-C: $25 \mathrm{~s}$ long epoch of mental calculation. Between the trials $60 \mathrm{~s}$ rest period was provided.

B. Schema of collecting running average data. Average blood flow velocity values of $5 \mathrm{~s}$ periods were calculated with $0.5 \mathrm{~s}$ stepping (horizontal thin lines with vertical arrows). The mean systolic (syst) and diastolic (diast) flow velocity curves were plotted after splicing the distinct running average values. The thin continuous line indicates the actual blood flow velocity values. The sampling method was the same for all autonomic variables. BFV: blood flow velocity. 
TABLE 1. Blood flow velocity and autonomic parameter data in the mental arithmetic test.

\begin{tabular}{|c|c|c|c|c|}
\hline Parameters & $\begin{array}{c}\text { Average of absolute values } \\
\text { of the reference period } \\
\text { (mean } \pm \text { S.D.) }\end{array}$ & $\begin{array}{c}\text { Relative MAX/MIN } \\
\text { values (mean } \pm \text { S.D.) } \\
(\%)\end{array}$ & $\begin{array}{c}\text { Time of MAX/MIN } \\
\text { values }(s)\end{array}$ & $\begin{array}{c}p \\
\text { value }\end{array}$ \\
\hline \multirow{2}{*}{$\begin{array}{l}\text { BFV } \\
\text { Left }\end{array}$} & \multirow{2}{*}{$\begin{array}{c}61.0 \pm 11.0 \\
(\mathrm{~cm} / \mathrm{s})\end{array}$} & MAX $_{1}: 6.6 \pm 4.1$ & 8.5 & $<0.001$ \\
\hline & & $\mathrm{MAX}_{2}: 7.7 \pm 3.8$ & 34.0 & $<0.001$ \\
\hline \multirow{2}{*}{$\begin{array}{l}\text { BFV } \\
\text { Right }\end{array}$} & \multirow{2}{*}{$\begin{array}{l}56.8 \pm 10.6 \\
\quad(\mathrm{~cm} / \mathrm{s})\end{array}$} & $\operatorname{MAX}_{1}: 5.6 \pm 4.2$ & 7.5 & $<0.001$ \\
\hline & & $\mathrm{MAX}_{2}: 7.1 \pm 4.3$ & 34.5 & $<0.001$ \\
\hline \multirow{3}{*}{$\begin{array}{l}\text { CVR } \\
\text { Left }\end{array}$} & \multirow{3}{*}{$\begin{array}{c}1.49 \pm 0.40 \\
(\mathrm{mmHg} * \mathrm{~s}) / \mathrm{cm}\end{array}$} & $\mathrm{MIN}_{1}:-1.0 \pm 5.5$ & 3.0 & $<0.05$ \\
\hline & & $\mathrm{MIN}_{2}:-5.7 \pm 5.8$ & 44.0 & $<0.05$ \\
\hline & & MAX: $2.2 \pm 5.6$ & 22.0 & $<0.05$ \\
\hline \multirow{3}{*}{$\begin{array}{l}\text { CVR } \\
\text { Right }\end{array}$} & \multirow{3}{*}{$\begin{array}{c}1.60 \pm 0.45 \\
(\mathrm{mmHg} * \mathrm{~s}) / \mathrm{cm}\end{array}$} & $\mathrm{MIN}_{1}:-0.7 \pm 4.8$ & 3.0 & ns \\
\hline & & $\mathrm{MIN}_{2}:-6.6 \pm 4.6$ & 44.0 & $<0.05$ \\
\hline & & MAX: $4.0 \pm 5.3$ & 22.0 & $<0.05$ \\
\hline $\mathrm{ABP}$ & $\begin{array}{c}87.6 \pm 12.8 \\
(\mathrm{mmHg})\end{array}$ & MAX: $6.2 \pm 5.5$ & 10.5 & $<0.001$ \\
\hline HR & $\begin{array}{l}78.7 \pm 13.2 \\
(1 / \mathrm{min})\end{array}$ & MAX: $16.7 \pm 6.6$ & 33.5 & $<0.001$ \\
\hline $\mathrm{Rr}$ & $\begin{array}{l}14.7 \pm 3.7 \\
\quad(1 / \mathrm{min})\end{array}$ & MAX: $28.6 \pm 14.0$ & 21.5 & $<0.001$ \\
\hline $\mathrm{ETP}_{\mathrm{CO}_{2}}$ & $\begin{array}{l}37.4 \pm 6.0 \\
\quad \text { (Torr) }\end{array}$ & MIN: $-10.9 \pm 7.8$ & 8.5 & $<0.001$ \\
\hline
\end{tabular}

$\mathrm{BFV}$, blood flow velocity; CVR, cerebral vascular resistance index; ABP, arterial blood pressure; HR, heart rate; Rr: respiratory rate; $\mathrm{ETP}_{\mathrm{CO}_{2}}$, end tidal $\mathrm{P}_{\mathrm{CO}_{2}}$; Relative $\mathrm{MAX} / \mathrm{MIN}$ values, average difference between the relative baseline and the relative maximum/minimum values; Time of MAX/MIN values, time at which the average MAX or MIN values were detected; ns, non-significant.

locity, ABPsys is the peak systolic and ABPdia is the end diastolic blood pressure respectively.

End tidal partial pressure of $\mathrm{CO}_{2}\left(\mathrm{ETP}_{\mathrm{CO}_{2}}\right.$; Torr $)$ was recorded with the capnograph of the above described tonometer using a soft plastic mask, which was fixed on the face of the subject.

Heart rate (HR; $1 / \mathrm{min}$ ) was calculated from the ABP systolic peak-to-peak distance.

Respiratory rate $(\mathrm{Rr} ; 1 / \mathrm{min})$ was calculated on the basis of peak intervals of $\mathrm{ETP}_{\mathrm{CO}_{2}}$ curves using the following equation:

Eq. 3: $\mathrm{Rr}=60 /$ interpeak $\mathrm{ETP}_{\mathrm{CO}_{2}}$ interval.

Cerebral vascular resistance index $(\mathrm{CVR}, \mathrm{mmHg} \times \mathrm{s} / \mathrm{cm})$ is the ratio of the actual $\mathrm{ABP}$ and $\mathrm{BFV}$ values (Brys et al. 2003; Koch et al. 2005) and it was calculated using equation 4 :

$$
\text { Eq. } 4: \mathrm{CVR}=\mathrm{ABP} / \mathrm{BFV}
$$

The maximum and minimum relative values of the parameters were searched using an automatic program. The average difference between the baseline and the maximum value was defined as $\mathrm{MAX}_{1}$ and $\mathrm{MAX}_{2}$, while between the baseline and the minimum value as $\mathrm{MIN}_{1}$ and $\mathrm{MIN}_{2}$ (Table 1). We also measured the latency between the presentation of the mental arithmetic task and MAX/MIN values of the parameters.

\section{Experimental paradigms}

Voluntary hyperventilation: for testing the effect of voluntary hyperventilation, subjects were instructed to breathe deeply for $2 \mathrm{~min}$ - utes during which BFV and the autonomic parameters were simultaneously monitored. This test also served to confirm the stability and sensitivity of TCD and tonometric sensors.

Mental arithmetic (MA) paradigm: we used a mental calculation test to induce cerebral activation (Burbaud et al. 1999). Subjects were instructed to subtract sequentially the same number from a triple- or double-digit number close to 100 (i.e.: $102-8=94,94-8=86,86$ $-8=78$, etc). A different number (between 6 and 9) to be subtracted was given at the beginning of each subtraction task (Kazui et al. 2000; Szirmai et al. 2005). The trial started with a cueing tone (a $32 \mathrm{~ms}$ long, $560 \mathrm{~Hz}$ "bip") at time 0 (signal-a) when the task was presented through the loudspeaker. Five seconds later (signal-b) the subject started the calculation. After $25 \mathrm{~s}$ (period-C) signal-c indicated the end of calculation, and $5 \mathrm{~s}$ later at signal-d the subject had to announce the result (Fig. 1A). A $60 \mathrm{~s}$ resting-period followed each trial. Data of 10 trials, each with a different subtraction task, were collected.

\section{Statistical analysis}

Group average BFV and autonomic variable data were given as mean \pm standard deviation (S.D.). Reference values were calculated from the period between $-15 \mathrm{~s}$ to $-3 \mathrm{~s}$ before the start of voluntary hyperventilation or before signal- $a$ in the mental calculation test (Fig. 1A). In the cognitive trial, we calculated the average increase of BFV in the $\pm 2 \mathrm{~s}$ period around the first BFV peak that is between the 6.5$10.5 \mathrm{~s}$ of the trial (Fig. 3. left upper panel, BFV horizontal double arrow).

The distribution of all examined values passed the KolmogorovSmirnov normality test. For statistical analysis, relative values of the 
parameters were calculated according to equation 5:

Eq. 5: Xrel $[\%]=($ Xact - Xref $) / X$ ref* $100+100$;

where Xact is the actual absolute value of the given parameter at a given time, Xref is the mean value of the reference period (from -15 to $-3 \mathrm{~s}$ of the pre-stimulus interval) of the same parameter.

We used repeated-measures of ANOVA test to find significant differences between the values of the reference and the cognitive period as well as MAX and MIN values of all parameters. The within subject factors for all parameters were the reaction (baseline, actual, MAX and MIN values of reactions), and in case of BFV and CVR the side (left and right) as well. In case of significant effect the NeumannKeuls post hoc test was performed.

Reactions of the 2 minutes long voluntary hyperventilation were also evaluated by ANOVA method. The level of significance was $p<$ 0.05 in all tests.

Cross correlation index was calculated for the corresponding 40 - 40 distinct values of CVR and $\mathrm{ETP}_{\mathrm{CO}_{2}}$ from the first $20 \mathrm{~s}$ of period-C. The level of significance of the correlation coefficient was determined according to the $t$-distribution threshold value (2.022); the degree of freedom (df) was 38.

All statistical analysis was performed using Statistica 7.1 sofware (Statsoft Incorporation, Tulsa, OK, USA) software.

\section{Results}

\section{Voluntary hyperventilation}

$\mathrm{ETP}_{\mathrm{CO}_{2}}$ began to decrease $5 \mathrm{~s}$ after starting the voluntary hyperventilation and decreased continuously until the end of the 2 minutes long trial reaching significantly lower levels compared to baseline already at $10 \mathrm{~s}$ (Fig. 2). By the end of the trial $\mathrm{ETP}_{\mathrm{CO}_{2}}$ was decreased by $26.2 \pm 13.4 \%$ compared to the pre-test period.

At the beginning of hyperventilation BFV increased significantly on both sides (by $6.0 \pm 6.1 \%$ ), but after $11 \mathrm{~s}$ it started to decrease, and another $8 \mathrm{~s}$ later it became significantly slower compared to the baseline. After 2 minutes hyperventilation, the BFV was by $24.5 \pm 6.4 \%$ lower than the reference value. The timing and degree of BFV changes in the two hemispheres were similar; therefore the left-right difference was close to zero (Fig. 2).

During voluntary hyperventilation a transient significant increase of ABP (by $6.2 \pm 8.1 \%$ compared to baseline) was recorded between the 7.5 - 12.5 s of hyperventilation, after which the blood pressure returned to the baseline.

Elevation of heart rate reached significance only after $25 \mathrm{~s}$ when it became $14.6 \pm 12.3 \%$ higher compared to baseline. This slow increase was followed by a plateau until the end of the hyperventilation task (Fig. 2).

The cerebral vascular resistance index increased during voluntary hyperventilation on both sides and it became significantly higher compared to the baseline, at $17.5 \mathrm{~s}$ on the left and $20.5 \mathrm{~s}$ on the right side.

The respiratory rate did not increase, since subjects were instructed to breathe deeply but not fast.
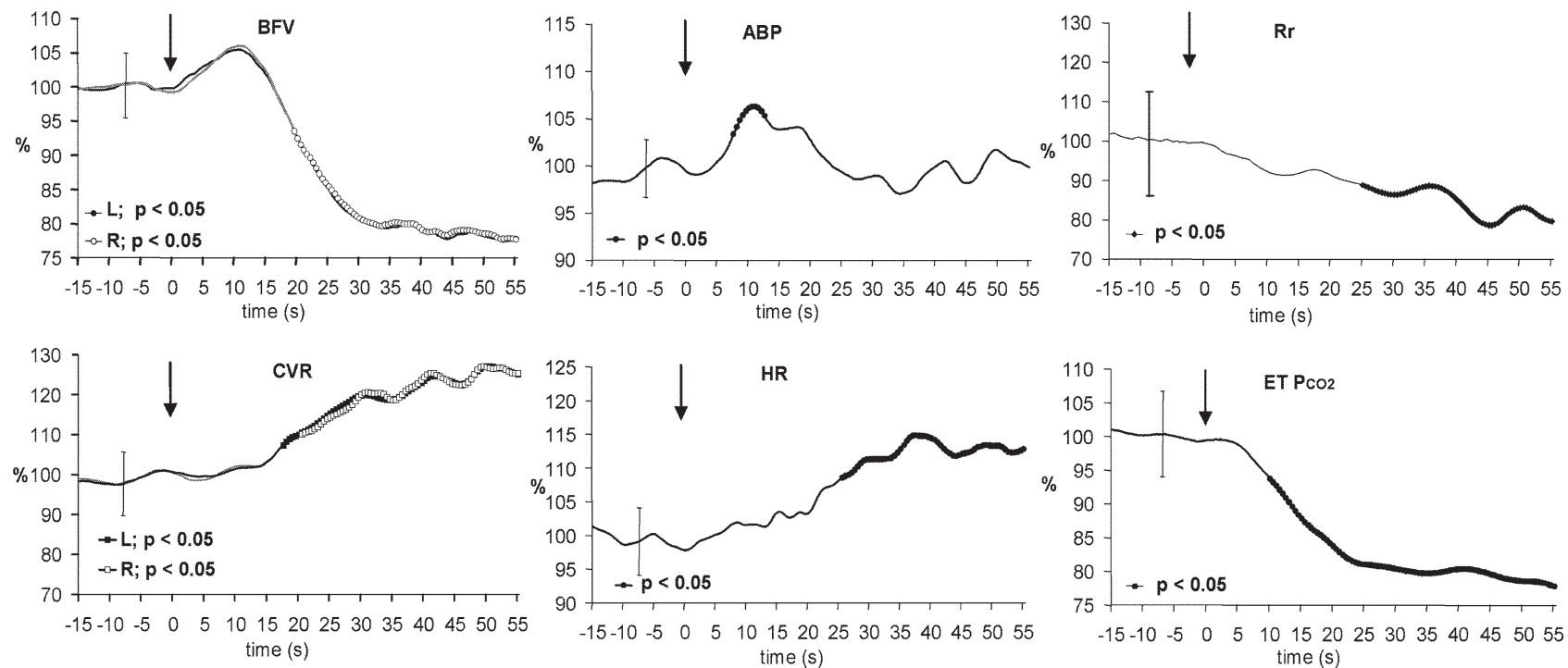

Fig. 2. Percentage change of blood flow velocity and autonomic variables during voluntary hyperventilation.

Subjects started hyperventilation at time 0 (marked by arrows). Solid lines in each panel represent relative average values of all 16 subjects. In the left upper panel, relative means of BFV of the left (black line) and right (grey line) side are shown. In the left lower panel, relative means of CVR of the left (black line) and right (grey line) side are presented. Vertical thin lines represent S.D. values, which are similar in the reference and hyperventilation periods. Full and empty circles depict those values, which are significantly lower (in case of BFV and $\mathrm{ETP}_{\mathrm{CO}_{2}}$ and $\mathrm{CVR}$ ) or higher (in case of $\mathrm{ABP}$ and HR) compared to the mean of the reference epoch (the period between $-15 \mathrm{~s}$ to $-3 \mathrm{~s}$ ) determined by ANOVA statistics $(p<0.05)$. Note that due to similar changes of BFV on the two sides the symbols for left and right data cover each other.

L: left; R: right; BFV: blood flow velocity; ABP: arterial blood pressure; Rr: respiratory rate; CVR: cerebral vascular resistance; $\mathrm{HR}$ : heart rate; $\mathrm{ETP}_{\mathrm{CO}_{2}}$ : end-tidal $\mathrm{P}_{\mathrm{CO}_{2}}$. 

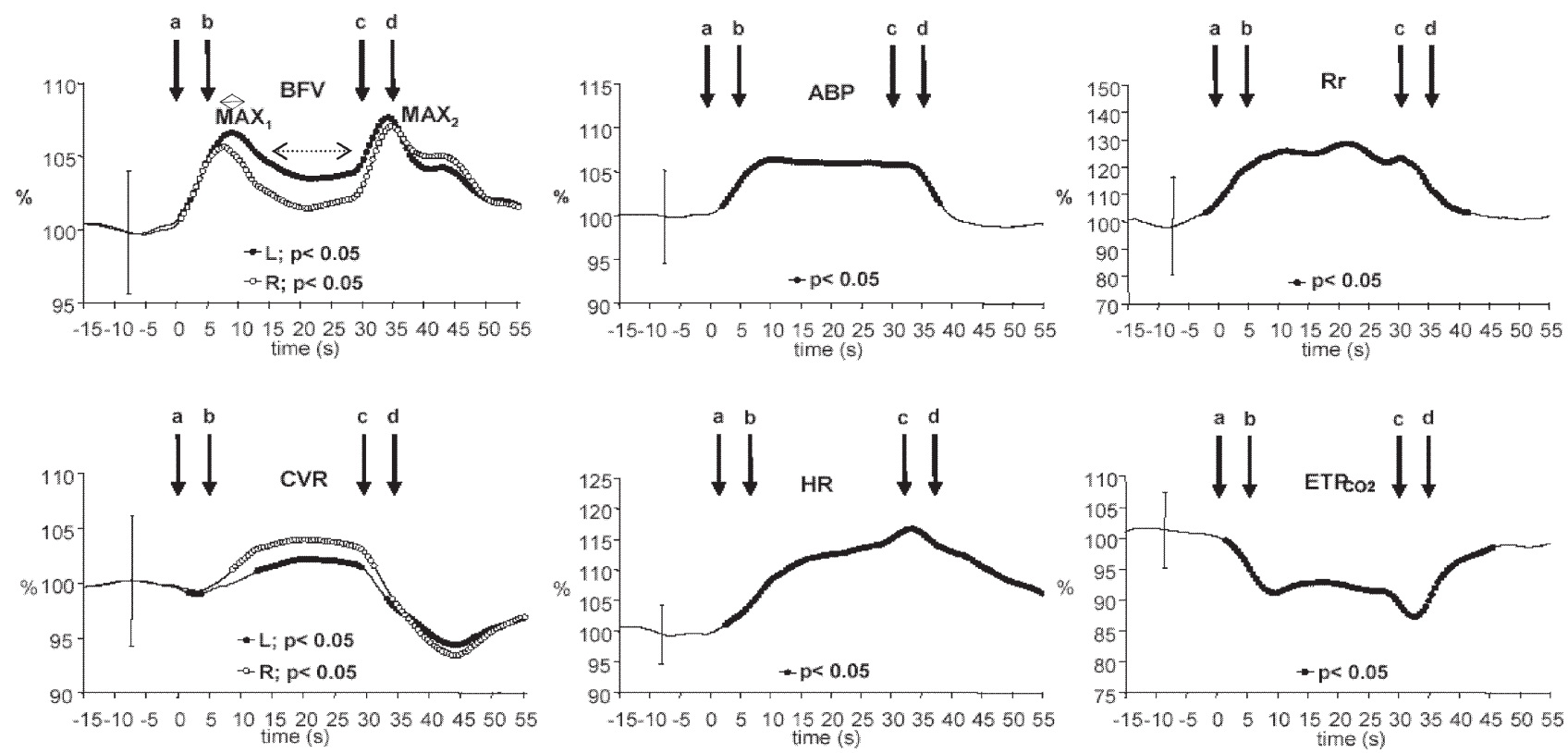

Fig. 3. Percentage change of blood flow velocity and autonomic variables during mental arithmetic task. Solid lines in each panel represent relative average values of all 16 subjects. In the left upper panel, relative mean BFV data of the left (black line) and right (grey line) side are shown. The horizontal double arrow shows the $\pm 2 \mathrm{~s}$ period around $\mathrm{MAX}_{1}$ where the average maximum value was calculated. The horizontal broken double arrow shows the period during which the BFV was significantly lower compared to the mean maximum. In the left lower panel, relative mean CVR data of the left (black line) and right (grey line) side are presented. Vertical thin lines represent S.D. values, which are similar in the reference periods and in the cognitive epochs. Full and empty circles depict those values which are significantly different from the mean of the reference epoch (the period between $-15 \mathrm{~s}$ to $-3 \mathrm{~s}$ ) determined by ANOVA statistics $(p<0.05)$. L: left; R: right; BFV: blood flow velocity; ABP: arterial blood pressure; Rr: respiratory rate; CVR: cerebral vascular resistance index; $\mathrm{HR}$ : heart rate; $\mathrm{ETP}_{\mathrm{CO}_{2}}$ : end-tidal $\mathrm{P}_{\mathrm{CO}_{2}} ; \mathrm{MAX}_{1}$ : first maximum peak of $\mathrm{BFV} ; \mathrm{MAX}_{2}$ : second maximum peak of BFV; for signals $a, b, c$ and $d$ see Fig. 1 .

\section{Mental arithmetic test}

Average of the absolute values of the reference period and the difference between the relative baseline and the maximum (MAX) and minimum (MIN) values of all parameters, as well as the relevant $p$ values are presented in Table 1.

\section{Blood flow velocity changes}

After signal-a BFV elevated on both sides, and from the first second its level remained significantly higher than baseline until $64.5 \mathrm{~s}$ on the left and $63 \mathrm{~s}$ on the right side. During the $25 \mathrm{~s}$ cognitive effort, in all subjects, BFV showed a uniform "waxing-waning-waxing" pattern with two maxima $\left(\mathrm{MAX}_{1}, \mathrm{MAX}_{2}\right)$ (Fig. 3). The average increase of BFV in the $\pm 2 \mathrm{~s}$ period around the first BFV peak (that is between the $6.5-10.5 \mathrm{~s}$ ) was $6.3 \pm 4.1 \%$ on the left and $4.7 \pm 4.0$ on the right side. After the first peak, BFV started to drop on both sides and all values between $15-30$ $\mathrm{s}$ of the cognitive trial were significantly lower compared to the maximum (Fig. 3). The diminution of blood flow velocity during mental calculation was less pronounced on the left side therefore, the left-right BFV difference became positive. The maximum left-right difference value was 2.1 $\pm 1.1 \%$ at the time of $21 \mathrm{~s}$.
Respiratory rate and end-tidal $\mathrm{P}_{\mathrm{CO}_{2}}$

The respiratory rate increased during mental arithmetic and it became significantly higher compared to the reference period between $2.5 \mathrm{~s}$ and $41.5 \mathrm{~s}$ (Fig. 3).

The $\mathrm{ETP}_{\mathrm{CO}_{2}}$ decreased significantly between $4.5 \mathrm{~s}$ and $41.5 \mathrm{~s}$ in correlation with the elevated respiratory rate (Fig. $3)$. The shape of the $\mathrm{ETP}_{\mathrm{CO}_{2}}$ curve was the opposite of the BFV diagram.

\section{Arterial blood pressure and heart rate}

During mental calculation, significant elevation of arterial blood pressure was observed in all but one of the subjects. After signal-a blood pressure started to increase and between 2 and $38 \mathrm{~s}$ it remained significantly higher than baseline.

Significant elevation of heart rate developed in all subjects between 2.5 and $70 \mathrm{~s}$ (Fig. 3).

\section{Cerebral vascular resistance index}

After signal- $a$ a transient decrease of CVR occurred in both hemispheres, which was followed by a significant elevation (on the left side between $12.5 \mathrm{~s}$ and $29 \mathrm{~s}$; on the right side between 8.5 and $31 \mathrm{~s}$ ). After announcing the result of the calculation, a significant decrease was found on both sides (on the left side between $33 \mathrm{~s}$ and $70 \mathrm{~s}$; on the right side between 34 and 70 s) (Fig. 3). The maximum left-right 

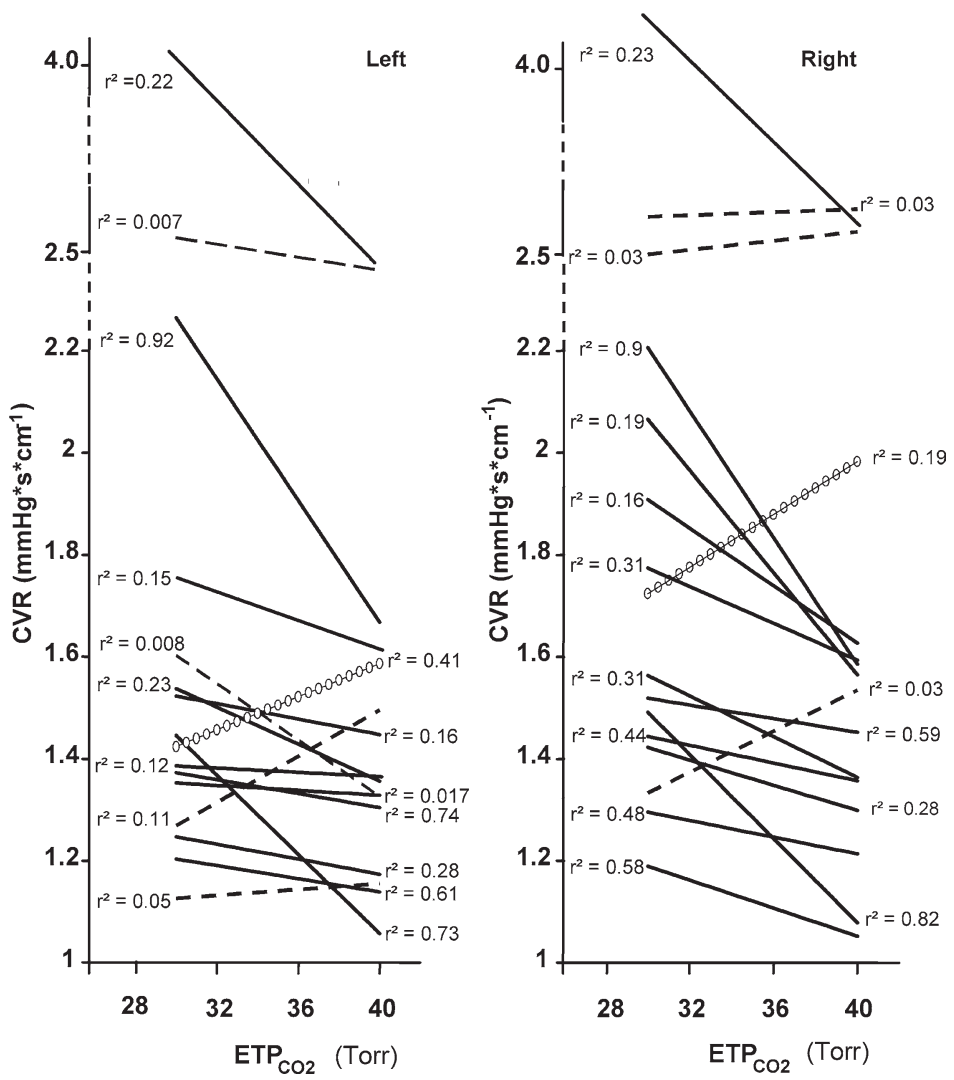

Fig. 4. Linear correlation functions for end-tidal $\mathrm{P}_{\mathrm{CO}_{2}}$ and cerebral vascular resistance index. Linear correlation functions for end-tidal $\mathrm{P}_{\mathrm{CO}_{2}}$ and cerebral vascular resistance index (CVR) were calculated for the left and right middle cerebral artery during the first $20 \mathrm{~s}$ of cognitive effort in all subjects. Dark solid lines indicate individuals with significant negative correlation; empty circles, individuals with significant positive correlation; broken lines, individuals with no correlation.

difference of cerebral vascular resistance index was $-2.1 \pm$ $1.9 \%$ (at the time of $19 \mathrm{~s}$ ).

\section{Correlation between cerebral vascular resistance index and $\mathrm{ETP}_{\mathrm{CO}_{2}}$}

During the first $20 \mathrm{~s}$ of the cognitive period the correlation between $\mathrm{ETP}_{\mathrm{CO}_{2}}$ and cerebral vascular resistance index calculated for the left and right side was significantly negative in 11 out of 16 and in 12 out of 16 subjects respectively (Fig. 4).

\section{Discussion}

The alteration of blood flow velocity in intracranial arteries induced by cognition depends on various factors, for instance on the difficulty of mental processing (Kelley et al. 1992; Vingerhoets and Stroobant 1999). Mental arithmetic is a complex and demanding paradigm, which simultaneously affects mechanisms of attention, emotion, visual imagination, working- and long-term memory, etc. (Gruber et al. 2001), and it is associated with intense systemic autonomic reactions including involuntary hyperventilation. In functional neuroimaging experiments investigating cognitive processes, the rate of respiration and/or the changes of $\mathrm{ETP}_{\mathrm{CO}_{2}}$ are usually not registered, primarily due to technical complications. Therefore, it is difficult to determine wheth- er regional signal-changes during cognitive tasks are exclusively related to mental activity or they are partially confounded by respiratory or other concomitant systemic autonomic effects (Birn et al. 2008). According to the observations of Posse et al. (1997), hyperventilation during functional neuroimaging experiments may distort fMRI signals.

To assess the effect of respiratory changes induced by cognition on cerebral circulation, we measured blood flow velocity using transcranial Doppler sonography and simultaneously recorded the respiratory and cardiac autonomic parameters during voluntary hyperventilation without cognitive task and during mental arithmetic test. As expected, voluntary hyperventilation caused a significant alveolar hypocapnia proved by the decrease of $\mathrm{ETP}_{\mathrm{CO}_{2}}$. During mental arithmetic $\mathrm{ETP}_{\mathrm{CO}_{2}}$ also decreased significantly because of involuntary hyperventilation, which was caused by the $47.4 \%$ increase of respiratory rate.

As it is well known, the most effective regulator of the diameter of resistance vessels in the brain is the partial $\mathrm{CO}_{2}$ pressure. Hypocapnia decreases blood flow velocity through the constriction of arterioles. Voluntary hyperventilation induced a significant decrease of BFV. By the end of the 2 min test period, blood flow velocity was about $30 \%$ less than the reference value, which can be explained by the 
vasoconstrictor effect of hypocapnia.

In the cognitive task, when the subject started the mental calculation (signal-a), an instantaneous elevation of blood flow velocity was observed on both sides, which coincided with a significant increase of blood pressure and heart rate. We propose that this symmetric steep elevation of flow velocity results from the increased perfusion pressure leading to passive blood filling depending on the intracranial reserve capacity. The increase of blood pressure could be related to arousal reaction caused by increased attention (LaBar et al. 1999; Szirmai et al. 2005) associating with a prompt dilatation of resistance vessels under the control of fast neurogenic (Sandor 1999) and/or local metabolic (Sheth et al. 2004) regulation. The time constant of metabolic coupling of vascular regulation of the cerebral blood flow is about 2 - $3 \mathrm{~s}$ (Sheth et al. 2004), which is compatible with our data.

Unexpectedly however, during mental calculation, the flow velocity started to decrease approaching the level of the reference period. The BFV drop occurred simultaneously with the significant reduction of $\mathrm{ETP}_{\mathrm{CO}_{2}}$ suggesting that hypocapnia through vasoconstriction reduced the blood flow velocity. This proposition is also supported by the significant elevation of the cerebral vascular resistance index during cognitive challenge, since decreased diameter of cerebral arterioles results in increased cerebral vascular resistance (Brys et al. 2003), as it was proved recently by TCD (Classen et al. 2007) and fMRI (Floyd et al. 2003) investigations.

According to the results of Kazui et al. (2000) serial subtraction activates the left intraparietal sulcus, the premotor and supplementary motor areas, and the posterior portion of the left inferior frontal gyrus. These cortical areas are supplied by the left middle cerebral artery. In our experiment, during serial subtraction, despite the bilateral decrease of BFV caused by hypocapnia, the blood flow velocity in the left MCA remained higher than in the right MCA in all subjects. This reflects the effect of local neural regulation of microcirculation in the activated hemisphere, and suggests the leading role of a neuronal activity-driven control of the diameter of resistance vessels, which is able to counteract the systemic effect of hypocapnia.

A second maximum of blood flow velocity was observed at the end of the cognitive trial preceded by a slight insignificant increase between the 20 and $30 \mathrm{~s}$ and a steep elevation between the 30 and $35 \mathrm{~s}$. One possible reason for the slight increase of BFV before finishing the calculation is that during repetition subjects probably learned the timing of the test and the expectancy period before reporting the results became longer. This trend could be observed in the consecutive trials of each individual suggesting the possibility of habituation. It is also possible that the use of running average method with $5 \mathrm{~s}$ analysis interval and $0.5 \mathrm{~s}$ stepping influenced the shape of the BFV curve by elevating the average values towards the end of the trial. The steep elevation just before announcing the result might be attributed to intrinsic neurogenic regulation of vessels rather than to perfusion-dependent passive flow, since in this period there were no additional changes of blood pressure. To elucidate the underlying mechanisms further experiments are needed.

We conclude that simultaneous events induced by cognition and related autonomic reactions (Rasia-Filho 2006) influence cerebral circulation. Our results suggest that hypocapnia, which develops during mental calculation, decreases BFV in the middle cerebral arteries, which interferes with the neuronal activity-driven regulation of cerebral circulation. We conclude that when interpreting the results of functional imaging studies on cognitive mechanisms, the tight coupling of the effects of mental processes and autonomic/metabolic reactions should be considered.

\section{Acknowledgments}

We thank László Pálvölgyi for his invaluable help in data analysis, Dr. Zsuzsanna Farkas for statistical suggestions and Dávid M. Gyurkó for computational work.

\section{References}

Birn, R.M., Smith, M.A., Jones, T.B. \& Bandettini, P.A. (2008) The respiration response function: The temporal dynamics of fMRI signal fluctuations related to changes in respiration. NeuroImage, 40, 644-654.

Brys, M., Brown, C.M, Marthol, H., Franta, R. \& Hilz, M.J. (2003) Dynamic cerebral autoregulation remains stable during physical challenge in healthy persons. Am. J. Physiol. Heart Circ. Physiol., 285, 1048-1054.

Burbaud, P., Camus, D., Guehl, B., Bioulac, J.M., Caille, M. \& Allard, M. (1999) A functional magnetic resonance imaging study of mental subtraction in human subjects. Neurosci. Lett., 273, 195-199.

Claassen, J.A., Zhang, R., Fu, Q., Witkowski, S. \& Levine, B.D. (2007) Transcranial Doppler estimation of cerebral blood flow and cerebrovascular conductance during modified rebreathing. J. Appl. Physiol., 102, 870-877.

Deppe, M., Ringelstein, E.B. \& Knecht, S. (2004) The investigation of functional brain lateralization by transcranial Doppler sonography. NeuroImage, 21, 1124-1146.

Droste , D.W, Harders, A.G. \& Rastogi, E. (1989) A transcranial Doppler study of blood flow velocity in the middle cerebral arteries performed at rest and during mental activities. Stroke, 20, 1005-1011.

Floyd, T.F., Clark, J.M., Gelfand, R., Detre, J.A., Ratcliffe, S., Guvakov, D., Lambertsen, C.J. \& Eckenhoff, R.G. (2003) Independent cerebral vasoconstrictive effects of hyperoxia and accompanying arterial hypocapnia at 1 ATA. J. Appl. Physiol., 95, 2453-2461.

Gruber, O., Indefrey, P., Steinmetz, H. \& Kleinschmidt, A. (2001) Dissociating neural correlates of cognitive components in mental calculation. Cereb. Cortex, 11, 350-359.

Hartje, W., Ringelstein, E.B., Kistinger, B., Fabianek, D. \& Willmes, K. (1994) Transcranial Doppler ultrasonic assessment of middle cerebral artery blood flow velocity changes during verbal and visuospatial cognitive tasks. Neuropsychologia, 32, 1443-1452.

Kazui, H., Kitagaki, H. \& Mori, E. (2000) Cortical activation during retrieval of arithmetical facts and actual calculation: A functional magnetic resonance imaging study. Psychiatry Clin. Neurosci., 54, 479-485.

Kelley, R.E., Chang, J.Y., Scheinman, N.J., Levin, B.E., Duncan, R.C. \& Lee, S.C. (1992) Transcranial Doppler assessment of 
cerebral flow velocity during cognitive tasks. Stroke, 23, 9-14.

Koch, A., Ivers, M., Gehrt, A., Schnoor, P., Rump, A. \& Rieckert, H. (2005) Cerebral autoregulation is temporarily disturbed in the early recovery phase after dynamic resistance exercise. Clin. Auton. Res., 15, 83-91.

LaBar, K.S., Gitelman, D.R., Parrish, T.B. \& Mesulam, M. (1999) Neuroanatomic overlap of working memory and spatial attention networks: a functional MRI comparison within subjects. NeuroImage, 10, 695-704.

Malatino, L.S., Bellofiore, S., Costa, M.P., Lo, M.G., Finocchiaro, F. \& Di Maria, G.U. (1992) Cerebral blood flow velocity after hyperventilation-induced vasoconstriction in hypertensive patients. Stroke, 23, 1728-1732.

Moody, M., Panerai, R.B., Eames, P.J. \& Potter, J.F. (2005) Cerebral and systemic hemodynamic changes during cognitive and motor activation paradigms. Am. J. Physiol. Regul. Integr. Comp. Physiol., 288, 1581-1588.

Nelesen, R.A. \& Dimsdale, J.E. (2002) Use of radial arterial tonometric continuous blood pressure measurement in cardiovascular reactivity studies. Blood Press. Monit., 7, 259-263.

Oldfield, R.C. (1971) The assessment and analysis of handedness: the Edinburgh inventory. Neuropsychologia, 9, 97-113.

Posse, S., Olthoff, U., Weckesser, M., Jancke, L., Muller-Gartner, H.W. \& Dager, S.R. (1997) Regional dynamic signal changes during controlled hyperventilation assessed with blood oxygen level-dependent functional MR imaging. Am. J. Neuroradiol., 18, 1763-1770.

Rasia-Filho, A.A. (2006) Is there anything "autonomous" in the nervous system? Adv. Physiol. Educ., 30, 9-12.

Sandor, P. (1999) Nervous control of the cerebrovascular system: doubts and facts. Neurochem. Int., 35, 237-259.

Schmidt, P., Krings, T., Willmes, K., Roessler, F., Reul, J. \& Thron,
A. (1999) Determination of cognitive hemispheric lateralization by "functional" transcranial Doppler crossvalidated by functional MRI. Stroke, 30, 939-945.

Sheth, S.A., Nemoto, M., Guiou, M., Walker, M., Pouratian, N. \& Toga, A.W. (2004) Linear and nonlinear relationships between neuronal activity, oxygen metabolism, and hemodynamic responses. Neuron, 42, 347-355.

Stroobant, N. \& Vingerhoets, G. (2000) Transcranial Doppler ultrasonography monitoring of cerebral hemodynamics during performance of cognitive tasks: a review. Neuropsychol. Rev., 10, 213-231.

Szirmai, I., Amrein, I., Pálvölgyi, L., Debreczeni, R. \& Kamondi, A. (2005) Correlation between blood flow velocity in the middle cerebral artery and EEG during cognitive effort. Cogn. Brain Res., 24, 33-40.

Vingerhoets, G. \& Stroobant, N. (1999) Lateralization of cerebral blood flow velocity changes during cognitive tasks. A simultaneous bilateral transcranial Doppler study. Stroke, 30, 2152-2158.

Wang, J., Rao, H., Wetmore, G.S., Furlan, P.M., Korczykowski, M., Dinges, D.F. \& Detre, J.A. (2005) Perfusion functional MRI reveals cerebral blood flow pattern under psychological stress. Proc. Natl. Acad. Sci. USA, 102, 17804-17809.

Weiss, E.M., Siedentopf, C., Hofer, A., Deisenhammer, E.A., Hoptman, M.J., Kremser, C., Golaszewski, S., Felber, S., Fleischhacker, W.W. \& Delazer, M. (2003) Brain activation pattern during a verbal fluency test in healthy male and female volunteers: a functional magnetic resonance imaging study. Neurosci. Lett., 352, 191-194.

Yoshino, K. \& Matsuoka, K. (2005) Causal coherence analysis of heart rate variability and systolic blood pressure variability under mental arithmetic task load. Biol. Psychol., 69, 217-227. 